Firstly, raised serum C.P.K. levels are usually accurate in identifying people affected by the myopathy. The levels may be only mildly raised, however, as exemplified by two of the propositi in this study, and also their predictive value seems to be much less in some families-for example, family $\mathrm{C}$-than in others-for example, family A. Secondly, increased sensitivity to all the pharmacological agents used and not only to halothane must be shown in order to be certain that a patient is affected by the myopathy, because a small contracture sometimes occurs in normal muscle when exposed to halothane though not to the other pharmacological agents. This is best exemplified by family $D$, where the muscle from the non-identical twin brother of the propositus gave a small contracture on exposure to halothane but did not show increased sensitivity to any other pharmacological agent and was therefore not considered to be malignant hyperpyrexia muscle.

This study therefore confirms that serum C.P.K. levels are usually reliable in screening relatives of patients who have suffered from malignant hyperpyrexia for the presence of the predisposing myopathy. But among people who may have raised C.P.K. levels for other reasons or in families where the rise in C.P.K. levels is equivocal affected individuals must be identified by testing their skeletal muscle for increased in-vitro pharmacological sensitivity.
R. F. W. Moulds is a postgraduate research scholar of the National Health and Medical Research Council. We are grateful to the Victor Hurley Research Fund of the Royal Melbourne Hospital for support. We are also indebted to Dr. R. McD. Anderson and Miss X. Dennett for the histological results, to $\mathrm{Mr}$. D. Wallace, Mr. G. Richardson, and Dr. R. Hjorth for the motorpoint biopsies, and to Dr. C. W. Baird for the serum biochemistry.

\section{References}

Britt, B. A., Kalow, W., Gordon, A., Humphrey, J. G., and Rewcastle, N. B. (1973). Canadian Anaesthetists' Society fournal, 20, 431

Denborough, M. A., Dennett, X., and Anderson, R. MCD. (1973). British Medical fournal, $1,272$.

Denborough, M. A., Ebeling, P., King, J. O., and Zapf, P. (1970). Lancet, 1, 1138.

Denborough, M. A., et al. (1974). Unpublished.

Ellis, F. R., Harriman, D. G. F., Keaney, N. P., Kyei-Mensah, K., and Tyrell,' J. H. (1971). British fournal of Anaesthesia, 43, 721.

Ellis, F. R., et al. (1972). British Medical fournal, 3, 559.

Isaacs, H., and Barlow, M. B. (1970). British Medical fournal, 1, 275.

Kalow, W., Britt, B. A., Terreau, M. E., and Haist, C. (1970). Lancet, 2, 895.

King, J. O., Denborough, M. A., and Zapf, P. (1972). Lancet, 1, 365.

King J. O, and Zapf, P. (1972). Medical fournal of Australia, 1, 699.

Moulds, R. F. W., and Denborough, M. A. (1974). British Medical fournal,

2, 241. F. W., and Denborough, M. A. (1972). British Medical fournal,
Moulds, R. F. 4,526 .

\title{
Diagnosis and Treatment of Essential Fatty Acid Deficiency in Man
}

\author{
M. PRESS, H. KIKUCHI, T. SHIMOYAMA， G. R. THOMPSON
}

British Medical fournal, 1974, 2, 247-250

\section{Summary}

Essential fatty acid deficiency was found on four occasions in three adult patients with malabsorption after intestinal resection. Diagnosis was primarily based on the gas chromatographic finding of the abnormal fatty acid 5, 8, 11- $(\omega 9)$ eicosatrienoic acid in plasma lecithin. None of the patients had received parenteral nutrition with a fat-free source of calories but all had been on a reduced intake of dietary fat at some stage. Treatment with intravenous Intralipid rapidly reversed the abnormal plasma fatty acid pattern and also cleared the rash in the patient wih he most severe deficiency.

\section{Introduction}

The two major essential fatty acids (E.F.A.) found in man are linoleic acid and arachidonic acid. Both are important constituents of cell membranes. Arachidonic acid is synthesized from linoleic acid in the liver but man, in common with all other vertebrates lacks the ability to synthesize linoleic acid de novo. Yeasts and plants, however, have enzymes capable

\footnotetext{
Department of Medicine, Royal Postgraduate Medical School, Hammersmith Hospital, London W12 OHS

M. PRESS, M.Sc., M.R.C.P., Registrar (Present address: M.R.C. Lipid Metabolism Unit, Hammersmith Hospital)

H. KIKUCHI, M.D., Research Assistant (Present address: Senior Lecture in Internal Medicine, Hirosaki University School of Medicine, Hirosaki, in Internal Medi,

T. SHIMOYAMAMA, M.D., Research Assistant (Present address: Professor of Internal Medicine, Hyogo College of Medicine, Nishinomiya, Hyogo, Japan)

G. R. THOMPSON, M.D., F.R.C.P., Senior Lecturer
}

of inserting the double bond between the sixth and seventh carbon atoms of a fatty acid chain (counting from the methyl end) which is the characteristic feature of both these essential fatty acids. Some of the commoner fatty acids found in man and the nomenclature used to describe them are shown in table I. All belong to the $\omega 6$ series. Thus Conversion of linoleic acid $(18: 2 \omega 6)$ to arachidonic acid $(20: 4 \omega 6)$ takes place via the formation of $8,11,14$-eicosatrienoic acid $(20: 3 \omega 6)$, whereas in essential fatty acid deficiency this process ceases and instead oleic acid $(18: 1 \omega 9)$ is converted to $5,8,11$ eicosatrenoic acid $(20: 3 \omega 9)$. The presence of significant amounts of the latter in plasma or tissue phospholipids is regarded as the biochemical hallmark of E.F.A. deficiency.

TABLE I-Major Fatty Acids Found in Man (after Coniglio, 1972)

\begin{tabular}{|c|c|c|c|c|c|}
\hline \multicolumn{5}{|l|}{ Common Name } & \multirow{2}{*}{$\begin{array}{l}\text { Abbreviated Formula } \\
\ldots \quad 16: 0\end{array}$} \\
\hline Palmitic acid & & 。 & & & \\
\hline tearic acid & . & .. & .. & $\cdots$ & . $18: 0$ \\
\hline Oleic acid & . & .. & . & $\cdots$ & $\begin{array}{ll}18: 1 \omega 9 \\
\cdots \quad 20: 3 \omega 9\end{array}$ \\
\hline 5,8,11-eicosatrienoic acid $\dagger$ & $\ddot{0}$ & 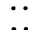 & $\because$ & $\because$ & 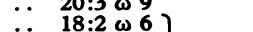 \\
\hline 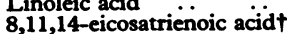 & $\because$ & $\because$ & $\therefore$ & $\because$ & $\therefore \quad 20: 3 \omega 6$ \\
\hline Arachidonic acid & .. & .. & .. & .. & .. $20: 4 \omega 6$ \\
\hline
\end{tabular}

* The abbreviated formula indicates the number of carbon atoms and the number of double bonds. The position of the double bond nearest to the methyl terminus, counting from same, is indicated by the symbol $\omega$.

This chemical terminology indicates the number of carbon atoms and the number of double bonds and their location, counting from the carboxyl terminus of the fatty acid.

Absence of E.F.A. from the diet has long been known to give rise to a specific deficiency syndrome in young animals, who fail to grow normally, develop a scaly dermatitis, and have widespread metabolic disturbances (Holman, 1971). A similar syndrome has been described in human infants fed milk formulae containing only saturated fat (Hansen et al., 
1963), but the first adult case has only recently been described (Collins et al., 1971). In that case and in other even more recent reports (Caldwell et al., 1972; Paulsrud et al., 1972; Jeejeebhoy et al., 1973) the onset of E.F.A. deficiency followed prolonged intravenous feeding with a fat-free source of calories.

We describe the clinical and biochemical features of four episodes of E.F.A. deficiency in three adult patients with malabsorption, none of whom had been receiving intravenous alimentation. Administration of intravenous linoleate in the form of Intralipid rapidly corrected all biochemical evidence of E.F.A. deficiency as well as the rash which was present in one patient. The fatty acid composition of plasma lipoproteins in these and other patients with malabsorption has already been reported (Shimoyama et al., 1973).

\section{Case Reports}

Case 1.-An 83-year-old man had a 15-year history of diabetes, treated at first with oral hypoglycaemic agents but since 1965 with insulin. In 1965 he developed thrombosis of his superior mensenteric artery, which necessitated resection of all the small bowel except for the proximal 14 inches $(35 \mathrm{~cm})$ of jejunum. He was placed on a $50-\mathrm{g}$ fat intake, on which his faecal fat excretion was $15 \mathrm{~g} /$ day.

Case 2.-A 45-year-old man had all but four feet $(1.2 \mathrm{~m})$ of jejunum and the distal half of his colon resected in 1954 after strangulation of a congenital volvulus. Since then he had had watery diarrhoea and a faecal fat excretion of 9-18 g/day on a 40-g fat intake.

Case 3.-A 64-year-old-woman had a hysterectomy in 1962 for carcinoma of the uterus, followed by a course of radiotherapy (4,000 rads). From 1966 she had repeated attacks of subacute intestinal obstruction. At an emergency laparotomy in May 1971 an extensively gangrenous small bowel was resected, leaving only the proximal three-four feet $(0 \cdot 9-1 \cdot 2 \mathrm{~m})$ of jejunum. To control her postoperative diarrhoea she was placed on a $30-\mathrm{g}$ fat intake, on which her faecal fat excretion was $20 \mathrm{~g} /$ day. Six months later she developed biochemical evidence of E.F.A. deficiency, which was treated with Intralipid. Within four months she again developed signs of E.F.A. deficiency, which included a scaly rash on both legs.

\section{Methods}

Blood samples were taken after an overnight fast and the fatty acid pattern of the lecithin, cholesterol ester and triglyceride fraotions of plasma lipids was determined by gas liquid chromatography (Shimoyama et al., 1973). Methyl esters of fatty acids were identified by comparing their $R f$ values with those of authentic standards and published data. A 5, 8, 11eicosatrienoic acid standard was obtained from the plasma of rats rendered deficient in essential fatty acids by dietary means. Each patient was then given a series of intravenous infusions of a soya bean oil emulsion in the form of 10 or $20 \%$ Intralipid (Vitrum, Stockholm), each litre of which contains 100 or $200 \mathrm{~g}$ triglyceride, of which over $50 \%$ is present as linoleate (18:2), and $12 \mathrm{~g}$ egg lecithin. The fatty acid composition of the triglyceride and lecithin components of Intralipid was analysed (table II). Each patient received a total of 1-2 1 . of 10 or $20 \%$ Intralipid at a rate of not more than 500 $\mathrm{ml}$ per day over 7-10 days. Details of individual dosage are shown in fig. 1. At least 24 hours after the end of the last infusion blood was again obtained in the fasting state and the fatty acid composition of plasma lipids reanalysed.

TABLE II-Fatty Acid Composition of Intralipid

\begin{tabular}{|c|c|c|c|c|c|c|c|}
\hline & & $\begin{array}{l}16: 0 \\
(\%)\end{array}$ & $\begin{array}{l}16: 1 \\
(\%)\end{array}$ & $\begin{array}{l}18: 0 \\
(\%)\end{array}$ & $\begin{array}{l}18: 1 \\
(\%)\end{array}$ & $\begin{array}{l}18: 2 \\
(\%)\end{array}$ & $\begin{array}{l}18: 3 \\
(\%)\end{array}$ \\
\hline $\begin{array}{ll}\text { Triglyceride } & . . \\
\text { Lecithin } & \ldots\end{array}$ & $\therefore$ & $\begin{array}{r}9 \cdot 7 \\
31 \cdot 7\end{array}$ & $\begin{array}{r}0 \\
1 \cdot 8\end{array}$ & $\begin{array}{r}3 \cdot 2 \\
12 \cdot 7\end{array}$ & $\begin{array}{l}24 \cdot 7 \\
28 \cdot 6\end{array}$ & $\begin{array}{l}52 \cdot 4 \\
13 \cdot 2\end{array}$ & $\begin{array}{r}8 \cdot 6 \\
0\end{array}$ \\
\hline
\end{tabular}

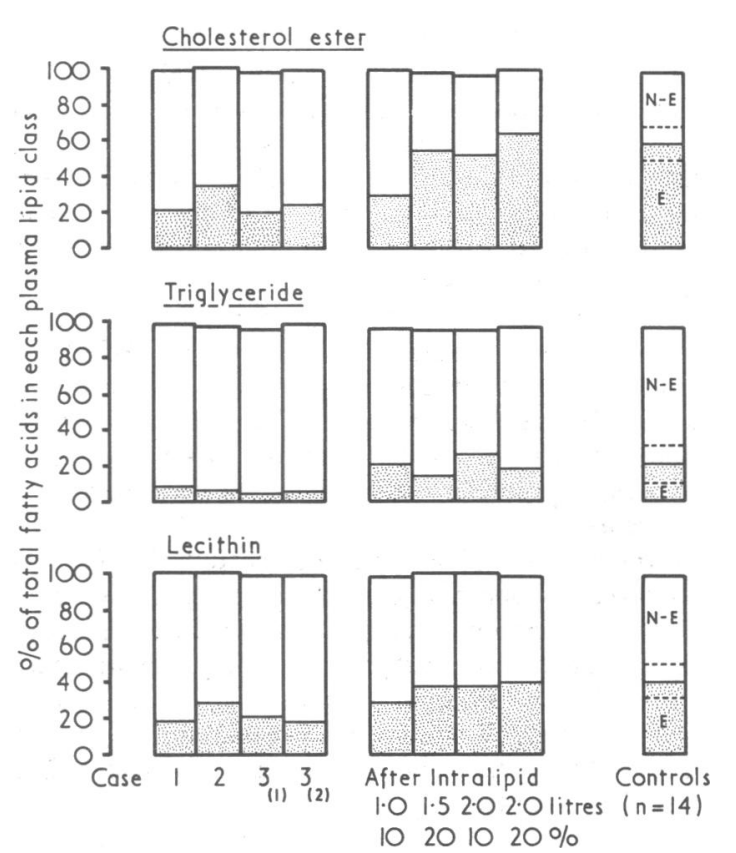

FIG. 1-Percentage of essential (E) and non-essential (N-E) fatty acids in plasma lipids of E.F.A.-deficient patients before and after treatment. The non-essential fatty acids have been calculated by summing percentage of palmitic (16:0), palmitoleic $(16: 1)$, stearic $(18: 0)$, oleic $(18: 1)$, and $5,8,11-$ eicosatrienoic $(20: 3 \omega 9)$ acids, whereas essential fatty acids represent sum of linoleic (18:2), 8,11,14-eicosatrienoic $(20: 3 \omega 6)$, and arachidonic $(20: 4)$ acids Quantity of $10 \%$ or $20 \%$ Intralipid administered to each patient is indicated below each histogram. Control values taken from data of Shimoyama et al. (1973) and represent mean \pm 2 S.D.

\section{Results}

The percentage of non-essential and essential fatty acids in the triglyceride, cholesterol ester, and lecithin fractions of whole plasma from the three patients, one of whom was studied on two separate occasions, is shown in fig. 1. It is evident that before treatment the patients had a severe deficiency of essential fatty acids. After the administration of Intralipid the percentage of essential fatty acids in each of the lipid classes rose to within normal limits in all but one patient (case 1), who had received the smallest dose.

The percentage of $\mathrm{C} 20$ fatty acids in the plasma lecithin of each patient is shown in table III. Each had detectable amounts of 5, 8, 11-eicosatrienoic acid (20:3 $\omega 9)$, an abnormal fatty acid not normally found in plasma, and an associated increase in the ratio $\begin{gathered}20: 3 \omega 9 \\ 20.4\end{gathered}$ to 0.4 or above. After Intralipid administration there was a rapid decrease in the percentage of 5, 8, 11-eicosatrienoic acid and an increase in arachidonic acid, with the result that the ratio $20: 3 \omega 9$ fell to $0 \cdot 1$. The effect of Intralipid on the fatty acid pattern of plasma lecithin in the most EFA-deficient patient (case 3) is illustrated in fig. 2.

TABle III-Percentage of C20 Fatty Acids in Plasma Lecithin of Patients before and after Intralipid Administration

\begin{tabular}{|c|c|c|c|c|c|c|}
\hline \multirow[t]{2}{*}{ Case No. } & \multicolumn{2}{|c|}{$20: 3 \omega 9$} & \multicolumn{2}{|c|}{$20: 4$} & \multicolumn{2}{|c|}{$\frac{20: 3 \omega 9}{20: 4}$} \\
\hline & Before & After & Before & After & Before & After \\
\hline $\begin{array}{l}1 \\
2 \\
3\end{array}$ & $\begin{array}{l}1.5 \\
4.8 \\
5.4 \\
7.5 \\
\end{array}$ & $\begin{array}{l}0.8 \\
0.8 \\
0.8 \\
1.3 \\
\end{array}$ & $\begin{array}{r}3.9 \\
11.1 \\
5.5 \\
5.8 \\
\end{array}$ & $\begin{array}{r}6.6 \\
12.9 \\
10.0 \\
12.3 \\
\end{array}$ & $\begin{array}{l}0.4 \\
0.4 \\
1.0 \\
1.3 \\
\end{array}$ & $\begin{array}{l}0.1 \\
0.1 \\
0.1 \\
0.1 \\
\end{array}$ \\
\hline Mean & $4 \cdot 8$ & 0.9 & $6 \cdot 6$ & $10 \cdot 5$ & 0.8 & 0.1 \\
\hline Control Value* & \multicolumn{2}{|c|}{0} & \multicolumn{2}{|c|}{$9 \cdot 3$} & \multicolumn{2}{|c|}{0} \\
\hline
\end{tabular}

\footnotetext{
* Data from Shimoyama et al. (1973).
} 


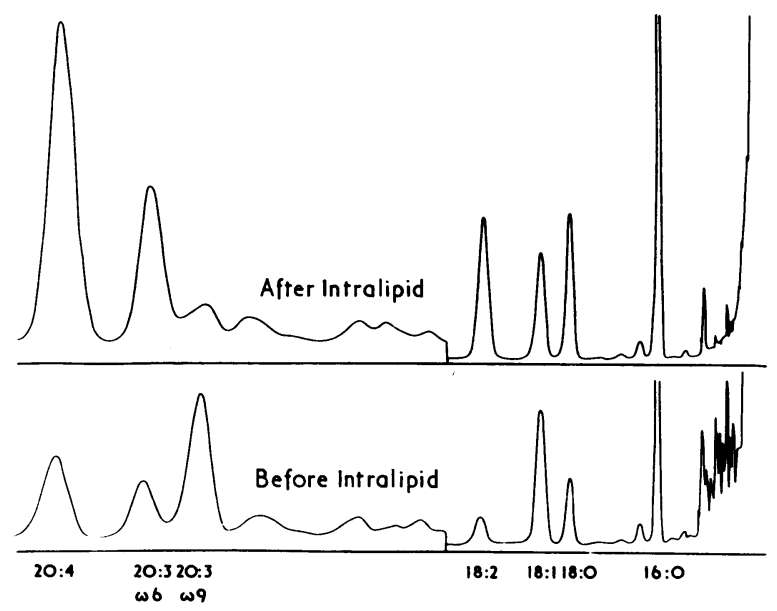

FIG. 2-Gas chromatograph of fatty acids in plasma lecithin in case 3 showing presence of abnormal 5,8,11-eicosatrienoic acid $(20: 3 \omega 9)$ before treatment. This disappears after administration of Intralipid, which also results in an increase in percentage of linoleic acid (18:2) and its metabolic products $8,11,14$-eicosatrienoic acid $(20: 3 \omega 6)$ and arachidonic acid $(20: 4)$. (Attenuation decreased ten-fold after emergence of $18: 2$.)

\section{Discussion}

We have already shown that though patients with malabsorption often have a decreased percentage of linoleic acid in their plasma lipids overt E.F.A. deficiency is relatively uncommon (Shimoyama et al., 1973). All three patients in the present study were included in our previous report but only two of them then had unequivocal biochemical evidence of E.F.A. deficiency. Subsequently one developed a rash associated with an increased propontion of $5,8,11$-eicosatrienoic acid in plasma lecithin and this abnormality became detectable in another patient. In all three malabsorption was secondary to major intestinal resections. This predilection for patients who have undergone intestinal resection cannot be explained simply by the severity of their steatorrhoea (Shimoyama et al., 1973). Other factors must be invoked, including the fact that such patients are often placed on a low-fat diet to control their diarrhoea. Collins et al. (1971) have calculated that an adult man requires at least $7.5 \mathrm{~g}$ linoleic acid per day, and probably a patient on a 30-50 $\mathrm{g}$ fat intake who has severe steatorrhoea absorbs less than this.

Diagnosis of E.F.A. deficiency depends on finding reduced amounts of both the major essential fatty acids, linoleic acid and arachidonic acid, and on the detection of the abnormal $5,8,11$-eicosatrienoic acid in plasma. A decrease in linoleic acid together with an increase in 5, 8, 11-eicosatrienoic acid but without a decrease in arachidonic acid, as occurred in one of our patients (case 2), has also been described (Collins et al., 1971; Mead, 1971).

Under normal circumstances lineoleic acid inhibits the synthesis of 5, 8, 11-eicosatrienoic acid from oleic acid (fig. 3). In the presence of severe linoleic acid deficiency however, not only is arachidonic acid synthesis decreased but the synthesis of $5,8,11$-eicosatrienoic acid is no longer inhibited, leading to its appearance in plasma lecithin. These changes can be quantitated by calculating the ratio $20: 3 \omega 9$. All our patients had ratios of 0.4 or over, which is reganded as pathognomonic of E F.A. deficiency (Holman 1971). In all instances this ratio decreased rapidly after the intravenous administration of 100 $300 \mathrm{~g}$ of linoleate in the form of Intralipid and the percentage of linoleate and arachidonate in plasma increased towards normal. One patient needed a second course of Intralipid four months after the first. This suggests that continuous surveillance is necessary once E.F.A. deficiency has been diag-

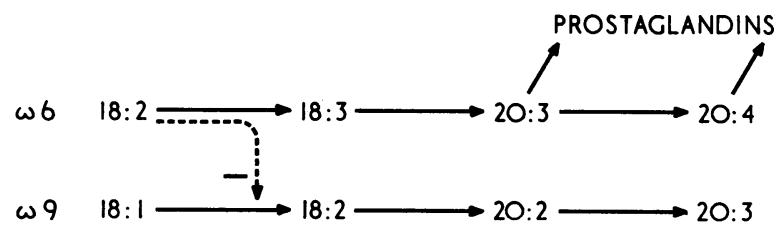

FIG. 3-Metabolic interconversion of fatty acids of $\omega 6$ and $\omega 9$ series. Diagrammatic representation of normal metabolic pathway of linoleic acid (18.2) to $\gamma$-linolenic acid $(18: 3)$, to $8,11,14$-eicosatrienoic acid $(20 \cdot 3 \omega 6)$ to arachidonic acid $(20: 4)$, and thence to prostalandins (Mead 1971; So arachi1972) 1972). Same enzme system can convert oleic acid $(18: 1)$ to 5,8,11-eicobiological activity of their $\omega 6$ isomers.
biolonic

nosed and when oral supplementation of the diet is impractical.

What are the metabolic consequences of E.F.A. deficiency in man? A scaly rash has been prominent both in experimental animals and in humans, and was present in our patient who had the most severe E.F.A. deficiency. It disappeared after the administration of Intralipid. Essential fatty acids are precursors of the prostaglandins (Samuelsson, 1972), so it is interesting that the skin lesions of E.F.A. deficiency respond to the topical application of prostaglandin $\mathrm{E}_{2}$ (Ziboh and Hsai, 1972). Prostaglandins are also known to influence platelet function in vitro, and it has been suggested that the increased tendency to platelet aggregation in rats (Hornstra, 1971) and in man (Hornstra et al., 1973) when fed diets low in linoleic acid may be due to reduced prostaglandin synthesis. Furthermore, E.F.A. deficiency has been shown to be associated with increased platelet adhesiveness and sensitivity to adenosine diphosphate-induced aggregation in vitro (Caldwell et al., 1972; Press et al., 1974 a ). It may therefore be relevant that the most severely E.F.A.-deficient of our patients (case 3 ) has had two cerebral and two coronary anterial occlusions since her intestinal resection. The first, immediately after the operation, may have been related to dehydration but the other three were unexplained.

Because of their malabsorption patients with intestinal resections are in precarious metabolic balance. E.F.A. deficiency in rats causes struotural changes in the intestinal mucosa (Snipes, 1968) and these are associated with malabsorption of sugars, amino-acids and fat (Snipes, 1968; Imami et al., 1970; Clark et al., 1973). Thus E.F.A. deficiency may further aggravate pre-existing malabsorption. Furthermore, widespread structural and functional disorganization of mitochondria (Wilson and Leduc, 1963) leads to an increase in the basal metabolic rate (Söderhjelm et al., 1971) and in caloric requirements. These factors have been held responsible for the reduced weight gain in E.F.A.-deficient growing animals and infants. Fatty liver is well recognized as a consequence of experimental E.F.A. deficiency in rats (Sinclair and Collins, 1968) and is a probable cause of the fatty liver sometimes seen after intestinal resection in humans (van Tongeren et al., 1972). Jeejeebhoy et al. (1973) described a patient who had undergone small intestinal resection in whom E.F.A. deficiency and a fatty liver developed during a period of intravenous feeding with a fat-free source of calories. Interestingly, both the E.F.A. deficiency and fatty liver were reversed by the administration of Intralipid. The clinical consequences of E.F.A. deficiency and the relative ease with which these can now be treated make the biochemical search for this syndrome a worthwhile task, especially in patients with postoperative malabsorption or malnutrition. Recent evidence, obtained by one of us after completion of the present study, suggests that the application of E.F.A. to the skin may be an alternative and effective route of administration (Press et al., 1974 b).

We are grateful to Miss Janet Heath for her expert technical help. This study was supported in part by a grant from Unilever. 


\section{References}

Caldwell, M. D., Johnson, H. T., and Othersen, H. B. (1972). Fournal of Pediatrics, 81, 894.

Clark, S. B., et al. (1973). Fournal of Lipid Research, 14, 581.

Collins, F. D., et al. (1971). Nutrition and Metabolism, 13, 150.

Coniglio, J. G. (1972). Federation Proceedings, 31, 1429.

Hansen, A. E., et al. (1963). Pediatrics, 31, 171. Holman, R. T. (1971). In Progress in the Chemistry of Fats and Other Lipids.
ed. R. T. Holman, Vol. 9. p, 275. Oxford, Pergamon.

Hornstra, G. (1971). Nutrition and Metabolism, 13, 140

Hornstra, G. (1971). Nutrition and Metabolism

Imami, R. H., Reiser, S., and Christiansen, P. A. (1970). Fournal of Nutrition, $100,101$.

Jeejeebhoy, K. N., et al. (1973). Gastroenterology, 65, 811.

Mead, J. F. (1971). In Progress in the Chemistry of Fats and Other Lipids, ed. R. T. Holman, Vol. 9, p. 159. Oxford, Pergamon.
Paulsrud, J., Pensler, L., Whitten, C. F., Stewart, S., and Holman, R. T. (1972). American fournal of Clinical Nutrition, 25, 897.

Press, M., Hartop, P. J., and Hawkey, C. (1974 a). Clinical Science. In press. Press, M., Hartop, P. J., and Prottey, C. (1974 b). Lancet. In press.

Samuelsson, B. (1972). Federation Proceedings, 31, 1442.

Shimoyama, T., Kikuchi, H., Press, M., and Thompson, G. R. (1973). Gut, 14, 716.

Sinclair, A. J., and Collins, F. D. (1968). Biochimica Biophysica Acta, 152, 498.

Snipes, R. L. (1968). Laboratory Investigation, 18, 179.

Söderhjelm, L., Wiese, H. F., and Holman, R. T. (1971). In Progress in the Chemistry of Fats and Other Lipids, ed. R. T. Holman, Vol. 9, p. 633. Oxford, Pergamon.

van Tongeren, J. H. M., et al. (1972). Folia Medica Neerlandica, 15, 246.

Wilson, J. W., and Leduc, E. H. (1963). Fournal of Cell Biology, 16, 281.

Ziboh, V. A., and Hsia, S. L. (1972). Fournal of Lipid Research, 13, 458.

\title{
Response to Rimiterol and Salbutamol Aerosols Administered by Intermittent Positive-pressure Ventilation
}

\author{
N. J. COOKE, J. A. KERR, R. F. WILLEY, MARGARET V. HOARE, I. W. B. GRANT, \\ G. K. CROMPTON
}

British Medical fournal, 1974, 2, 250-252

\section{Summary}

The bronchodilator and cardiac effects produced by aerosols of $0.5 \%$ salbutamol and $0.5 \%$ and $1 \%$ rimiterol administered for three minutes in $40 \%$ oxygen by intermittent positivepressure ventilation (I.P.P.V.) were compared in 15 asthmatic patients. Salbutamol and both the concentrations of rimiterol were equipotent in peak bronchodilator effect, but salbutamol had a significantly longer duration of bronchodilator action. There was significantly less increase in heart rate after rimiterol than after salbutamol. Aerosols of $0.5 \%$ rimiterol, $0.5 \%$ salbutamol, and saline were administered by I.P.P.V. to 10 normal volunteers. There was no difference between the mean heart rates after $0.5 \%$ rimiterol and saline but a highly significant increase in mean heart rate was observed after $0.5 \%$ salbutamol. It was concluded that $0.5 \%$ rimiterol was an effective short-acting bronchodilator drug with little or no cardiac beta ${ }_{1}$-adrenergic activity when administered for three minutes by I.P.P.V. in $40 \%$ oxygen.

\section{Introduction}

Rimiterol-erythro-(3, 4 dihydroxyphenyl (2-piperidyl) methanol hydrobromide-is a member of a new series of sympathomimetic amines, the aryl-2-piperidyl carbinols (Sankey and Whiting, 1972), in which the side chain is cyclized around the alpha-carbon atom to form a piperidyl ring. Invitro and in-vivo animal studies have shown rimiterol to have a preferential bronchodilator action with less cardiovascular activity than isoprenaline (Laity, 1971; Carney et al., 1971; Bowman and Rodger, 1972; Gailer et al., 1971). Studies

\footnotetext{
University Department of Respiratory Diseases and Respiratory Diseases Unit, Northern General Hospital, Edinburgh EH5 $2 D Q$ N. J. COOKE, M.B., M.R.C.P., Senior Registrar

J. A. KERR, M.B., CH.B., Senior House Officer

R. F. WILLEY, B.SC., M.B., Senior House Officer

I. W. B. GRANT, M.B., F.R.C.P., Consultant Physician

Department of Statistics, University of Edinburgh

MARGARET V. HOARE, M.SC., Lecturer
}

in volunteers and patients with asthma have shown rimiterol and isoprenaline equipotent weight-for-weight as bronchodilators (Turner and Griffin, 1971; Shenfield and Paterson, 1973), but rimiterol has been reported to have less chronotropic action on the heant than isoprenaline, Svedmyr et al., 1972; Griffin et al., 1973) and salbutamol (Phillips et al., 1972).

This investigation was planned to compare the bronchodilator properties and cardiac stimulant effects of rimiterol and salbutamol when administered by intermittent positivepressure ventilation (I.P.P.V.) using the technique described by Choo-Kang et al. (1970). Since these workers concluded that a $0.5 \%$ solution of salbutamol delivered by I.P.P.V. for three minutes provided "maximum bronchodilatation without important tachycardia" the same concentration of salbutamol was used in this study for comparison with rimiterol in $0.5 \%$ and $1 \%$ solutions.

\section{Patients and Methods}

The plan of the trial was similar to that described by ChooKang et al. (1970). Fifteen patients received for periods of three minutes on consecutive days aerosols of $0.5 \%$ rimiterol, $1 \%$ rimiterol, and $0.5 \%$ salbutamol and $40 \%$ oxygen delivered during each inspiratory cycle by I.P.P.V. from a Bennett ventilator. Patients received one of the treatments on each of three consecutive days. The sequence of drug administration was determined by a latin square experimental design. The identity of the drug and its concentration were unknown to the patient and medical observers. The highest of three readings of forced expiratory volume in one second $\left(F E V_{1}\right)$ from a Gaensler spirometer was recorded at 10 minutes, five minutes, and one minute before treatment and at $5,15,30,60$, 120,180 , and 240 minutes after treatment. The heart rate was read from a Hewlett-Packard cardiac monitor immediately before drug administration, at 5-minute intervals for 60 minutes afterwards, and thereafter at hourly intervals for the next three hours. The electrocardiograph was observed for arrhythmias during and for one hour after drug administration.

Ten normal volunteers were also studied in a subsidiary investigation and each received on consecutive days $0.5 \%$ rimiterol, $0.5 \%$ salbutamol, and saline. The sequence of drug administration was randomized and procedures and measure- 